\title{
RESEARCH
}

\section{FSH inhibits AMH to support ovarian estradiol synthesis in infantile mice}

\author{
Marie M Devillers ${ }^{1}$, Florence Petit ${ }^{1}$, Victoria Cluzet ${ }^{1}$, Charlotte M François ${ }^{1}$, Frank Giton ${ }^{2}$, Ghislaine Garrel' \\ Joëlle Cohen-Tannoudji1 and Céline J Guigon ${ }^{1}$
}

1Sorbonne Paris Cité, Université Paris-Diderot, CNRS, INSERM, Biologie Fonctionnelle et Adaptative UMR 8251, Physiologie de l'Axe Gonadotrope U1133, Paris, France

${ }^{2}$ APHP CIB GHU Sud Henri Mondor, INSERM IMRB U955, Eq.07, Faculté de Médecine, Créteil, France

Correspondence should be addressed to C J Guigon: celine.guigon@univ-paris-diderot.fr

\begin{abstract}
Anti-Müllerian hormone (AMH) regulates ovarian function in cyclic females, notably by preventing premature follicle-stimulating hormone (FSH)-mediated follicular growth and steroidogenesis. Its expression in growing follicles is controlled by FSH and by estradiol (E2). In infantile females, there is a transient increase in the activity of the gonadotrope axis, as reflected by elevated levels of both gonadotropins and E2. We previously demonstrated in mice that elevated FSH concentrations are necessary to induce E2 production by preantral/early antral follicles through the stimulation of aromatase expression without supporting their growth. However, whether this action of FSH could involve AMH is unknown. Here, we show that Amh mRNA and protein abundance and serum AMH levels are elevated in infantile mouse females, compared with those in adults. By experimentally manipulating FSH and E2 levels in infantile mice, we demonstrate that high FSH concentrations lower Amh expression specifically in preantral/early antral follicles, whereas E2 has no effect. Importantly, treatment of infantile ovaries in organotypic cultures with AMH decreases FSH-mediated expression of Cyp19a1 aromatase, but it does not alter the expression of cyclin D2-mediating granulosa cell proliferation. Overall, our data indicate that the infantile elevation in FSH levels suppresses Amh expression in preantral/early antral follicles, thereby favoring Cyp19a1 aromatase expression and E2 production. Together with recent discoveries that $\mathrm{AMH}$ can act on both the hypothalamus and the pituitary to increase gonadotropin levels, this work suggests that AMH is a critical regulator of the gonadotrope axis during the infantile period, thereby contributing to adult reproductive function programming.
\end{abstract} Key Words

Journal of Endocrinology (2019) 240, 215-228

\section{Introduction}

In mammals, the infantile period is characterized by a transient elevation in the levels of the two gonadotropins LH (luteinizing hormone) and FSH (follicle-stimulating hormone) shortly after birth (Döhler \& Wuttke 1975, Dullaart et al. 1975, Winter et al. 1975, Chellakooty et al. 2003, Kuiri-Hänninen et al. 2014). This process is accompanied by substantial gonadal activity as demonstrated by high sex steroid production in both sexes (estrogens and androgens in females and males, respectively) and by follicular growth in females. The resulting stimulation of gonadal activity, through sex steroid production, may be critical for the maturation 
of the genital tract and for brain sexualization, thereby contributing to the programming of adult reproductive function (Stewart \& Cygan 1980, Clarkson et al. 2009, Brock et al. 2011, Kuiri-Hänninen et al. 2013, Rey 2014).

The ovary is already receptive to gonadotropins during the infantile period, with FSH receptors (FSHR) expressed in granulosa cells and LH receptors (LHR) present in thecal cells (Fortune \& Eppig 1979, White \& Ojeda 1981, O'Shaughnessy et al. 1997). Similarly as in adult cyclic females, LH stimulates androgen synthesis in thecal cells, whereas FSH promotes the conversion of thecal-derived androgens into estrogens by aromatase in granulosa cells (Fortune \& Eppig 1979, White \& Ojeda 1981, O'Shaughnessy et al. 1997). In immature females, FSH would stimulate follicular growth from the primary stage onward, as suggested by rodent models (Halpin et al. 1986, Balla et al. 2003). We previously showed in the female mouse that circulating FSH levels are dramatically high during the infantile period at $~ 12-14$ days postnatal (dpn), reaching about five-fold those found in adult cycling females (François et al. 2017). We demonstrated that such FSH concentrations are necessary to induce Cyp19a1 aromatase expression in immature follicles at the preantral/early antral stage, thereby permitting estradiol (E2) production. These follicles belong to the first follicular waves, which started growing immediately after their formation at birth (Hirshfield \& DeSanti 1995). Notably, we showed that FSH does not support their growth due, at least in part, to its incapacity at high concentrations to induce the expression of the cell cycle regulator cyclin D2 (Ccnd2) and the proliferation of granulosa cells (François et al. 2017). Hence, the infantile elevation in FSH would contribute to E2 production from the first follicular waves without boosting their growth. However, the mechanisms underlying the preferential action of FSH on E2 biosynthesis over follicular growth during this period is unknown.

In the ovary, FSH regulates the expression of the antiMüllerian hormone (AMH, also called Müllerian-inhibiting substance or MIS) either positively (Taieb et al. 2011) or negatively (Baarends et al. 1995, Hardy et al. 2016, Roy et al. 2018), depending on the experimental model. AMH is a member of the transforming growth factor $\beta$ family, which in the ovary is specifically expressed in granulosa cells of growing follicles from the primary to the antral stage. The physiological actions of AMH in the ovary has been first demonstrated by analyses on Amh-knockout mice, which display premature ovarian failure owing to acceleration of follicular growth and primordial follicle recruitment into the growing follicle pool (Durlinger et al. 2001).
These data have led to the idea that AMH inhibits the recruitment of primordial follicles. Additional in vivo and in vitro studies have indicated that AMH may keep follicles insensitive to FSH-dependent growth (Durlinger et al. 2001) and to FSH-mediated steroidogenesis by inhibiting the expression and activity of aromatase (Grossman et al. 2008, Chang et al. 2013, Prapa et al. 2015, Sacchi et al. 2016). Hence, in growing follicles from adult cyclic females, the loss of AMH expression would allow FSHdependent growth and subsequent maturation associated with E2 synthesis (Visser \& Themmen 2014).

AMH is already expressed in infantile ovaries in mammals (Baarends et al. 1995, Mazaud et al. 2002, Hagen et al. 2010, Kuiri-Hänninen et al. 2011, Torres-Rovira et al. 2016, François et al. 2017). Given the known role of AMH and its regulation by FSH in mature ovaries, we made the hypothesis that there is already an interplay between FSH and AMH to regulate ovarian activity in immature females. Therefore, the present study aimed at addressing two issues: (1) could FSH already regulate $\mathrm{AMH}$ expression in growing follicles during the infantile period when gonadotropin levels and ovarian activity are both dramatically elevated; and (2) could AMH influence FSH action on the growth and steroidogenesis of prepubertal growing follicles? For that purpose, we analyzed the ontogenesis of $\mathrm{AMH}$ expression in prepubertal mice, and we investigated the possible regulatory action of FSH on the expression of AMH in infantile ovaries, by performing in vivo studies and organotypic cultures. We also determined whether AMH could modulate the action of FSH in the infantile ovary.

\section{Materials and methods}

\section{Animals and treatments}

Studies were conducted on C57BL/6JRj mice aged 7 to $27 \mathrm{dpn}$ and in adult cycling females that were born at the animal facility from genitors purchased at Janvier Labs (Le Genest St Isle, France). Mouse care and handling was performed as previously described (François et al. 2017). Ten micrograms of GnRH antagonist (Ganirelix, Orgalutran, N.V. Organon, Puteaux, France) or saline was subcutaneously injected twice on prepubertal female mice at 12 and $13 \mathrm{dpn}$, as previously described (François et al. 2017). In addition to Ganirelix, $13 \mathrm{dpn}$ mice received an intraperitoneal injection of $5 \mathrm{IU}$ of equine chorionic gonadotropin (eCG) (N.V.Organon), estradiol (8 pg/female, Sigma) or vehicle. Mice were then dissected at $14 \mathrm{dpn}$ to collect ovaries. Experiments were performed 
in accordance with standard ethics guidelines and were approved by Institutional Animal care and Use committee of the University Paris Diderot and by the French Ministry of Agriculture (agreement \#04015.01).

\section{In situ studies of Amh expression and cell death by TUNEL assay}

At least four prepubertal ovaries per age or treatment group were fixed for $1-2 \mathrm{~h}$ in $4 \%$ paraformaldehyde (PFA) depending on ovary size, rinsed in PBS and placed in $18 \%$ sucrose before being embedded in Optimal Cutting Temperature (Cellpath, Newtown, UK). In situ hybridization (ISH) was performed as previously described (Guigon et al. 2003) with digoxigenin-11-UTP labeled Amh RNA probes (accession number S98336, size: $653 \mathrm{bp}$ ) synthesized after cDNA amplification with Amh primers, forward 5'-ACCCCTTCCTAGAGACCCTCA and reverse 5'-GGTACGGGAACCACGTGGTG. Double staining with fibronectin was performed to visualize ovarian morphology and follicles. TUNEL assay was performed after ISH by incubating slides with a mix containing fluorescein-deoxy-UTP (TUNEL label, Roche) and terminal deoxynucleotidyltransferase (TUNEL enzyme, Roche) for $1 \mathrm{~h}$ at $37^{\circ} \mathrm{C}$. Cells exhibiting nuclear staining were considered as apoptotic. Negative controls lacking the labeling enzyme yielded no reaction product.

\section{Determination of serum AMH levels}

Quantification of AMH in the serum was performed using the commercial rat and mouse AMH ELISA kit (Ansh Labs, AL-113) following manufacturer's protocol. Briefly, diluted serum (1/10 for adults and $1 / 20$ for prepubertal females) and standards were added to AMH antibody-coated wells and incubated for $2 \mathrm{~h}$ at room temperature. After washing, wells were incubated with biotinylated AMH antibody for $1 \mathrm{~h}$, followed by incubation with streptavidin horseradish peroxidase conjugate for $30 \mathrm{~min}$. Then, the plate was developed using 3, 3', 5, $5^{\prime}$ tetramethylbenzidine (TMB) and the light absorbance was read at $450 \mathrm{~nm}$ using a microplate reader (FlexStation, Molecular device). Limit of ELISA sensitivity was $0.34 \mathrm{ng} / \mathrm{mL}$. The intra- and inter-assay variability was $1.6 \pm 0.53 \%$ and $5.7 \pm 1.6 \%$, respectively.

\section{Cultures of postnatal ovaries}

Ovaries from 12 to $13 \mathrm{dpn}$ female mice were placed on cell culture inserts (Millicell \#PICM01250, Millipore,
Guyancourt, France) on the top of $400 \mu \mathrm{L}$ of RPMI culture medium without red phenol containing fetuin (Sigma, \#F2379), insulin (Sigma, \#I0516), transferrin (Sigma, \#T8158), sodium selenite (Sigma, \#S5261) and BSA (Euromedex, Souffelweyersheim, France) in 24-well plates for $24 \mathrm{~h}$. Then, the culture medium was replaced with $400 \mu \mathrm{L}$ of fresh medium containing purified ovine pituitary FSH $(50,200$ or $500 \mathrm{ng} / \mathrm{mL})$ with or without the $25 \mathrm{kDa}$ C-terminal form of AMH $(400 \mathrm{ng} / \mathrm{mL}$ or $16 \mathrm{nM}$; R\&D, \#1737-MS-010), which can bind AMHRII and is a bio-active form (di Clemente et al. 2010). After $8 \mathrm{~h}$ of treatment, ovarian explants were snap-frozen in liquid nitrogen and stored at $-80^{\circ} \mathrm{C}$ for RNA extraction or fixed in 4\% PFA for histology, as described before (François et al. 2017).

\section{RNA extraction, reverse transcription and quantitative real-time PCR}

Single frozen ovaries were lysed with TissueLyser II (Qiagen) and RNA was obtained using RNeasy mini kit (\#74106, Qiagen), following manufacturer's protocol, as previously described (François et al. 2017). Total RNA (100 to $200 \mathrm{ng}$ ) was reverse transcribed using random primers and Superscript II (Invitrogen) following manufacturer's instructions. Primers used for quantitative real-time PCR are listed in Table 1. Real-time PCR was performed with Lightcycler 480 SYBR Green I Master and Lightcycler 480 instrument (Roche Molecular Biochemicals, La Rochelle, France), as previously described (François et al. 2017). Experiments were performed with at least four different ovarian samples/age or treatment group, with each sample run in triplicates.

\section{Western blot}

Pooled ( $n=2$ ovaries at $7 \mathrm{dpn}$ ) or single frozen ovaries were lysed with TissueLyser II (Qiagen) as described (François et al. 2017). Thirty micrograms of lysates were denatured under reducing conditions and used for the determination of AMH (antibody from R\&D Systems, \#AF1446), aromatase (Sigma, \#A7981), cyclin D2 (Santa-Cruz, \#sc-181) and GAPDH (Santa-Cruz, \#sc-25778). Western blot were performed as described (François et al. 2017).

\section{Determination of intra-ovarian estradiol content}

The mass spectrometry coupled with gas chromatography (GC-MS) procedure was used to determine E2 content in the infantile ovary. A single frozen ovary was 
Table 1 List of primers used for real-time PCR.

\begin{tabular}{|c|c|}
\hline Gene & Forward \\
\hline Сур19a1 & 5'-TACTTCATGTTACTTCTCGTCGC-3' \\
\hline Ccnd2 & 5'-CAGAAGGACATCCAGCCGTAC-3' \\
\hline Fshr & 5'-CTGGCATTCTTGGGCTCG-3' \\
\hline$A m h$ & 5'-TGCTAGTCCTACATCTGGCTGA-3' \\
\hline Foxo1 & 5'-CTTCAAGGATAAGGGCGACA-3' \\
\hline Glut1 & 5'-CATCCTTATTGCCCAGGTGTTT-3' \\
\hline Hprt & 5'-AGGACCTCTCGAAGTGT-3' \\
\hline
\end{tabular}

\begin{tabular}{lcc}
\hline Reverse & $\begin{array}{c}\text { Amplicon } \\
\text { size }(\mathrm{bp})\end{array}$ \\
\hline 5'-TATCCTCGATCTTTATGTCTCTGTCAC-3' & 103 \\
5'-TCGGGACTCCAGCCAAGAA-3' & 136 \\
5'-GGGCGGAATCTCGGTCA-3' & 101 \\
5'-GTCCAGGGTATAGCACTAACAGG-3' & 120 \\
5'-GACAGATTGTGGCGAATTGA-3' & 66 \\
5'-GAAGACGACACTGAGCAGCAGA-3' & 82 \\
5'-ATTCAAATCCCTGAAGTATCAT-3' & 111 \\
\hline
\end{tabular}

introduced into a Lysing Matrix D tube (MP Biomedicals, Illkirch-Graffenstaden, France) with cold saline water and deuterated methanol internal standard working solution. The sample was homogenized with Ribolyser (Hybaid, Teddington, Middlesex, UK). After centrifugation, the liquid phase with ceramic spheres was collected. The tissue residuals in Lysing Matrix tube were recovered in cold saline water and methanol (HPLC grade). After centrifugation, the organo-aqueous supernatant containing E2 was collected and evaporated. It was then purified in C18 Hypersep mini-columns (Thermo Fisher) and eluted with ethyl acetate (HPLC grade). The organic phase was evaporated to dryness, then reconstituted in saline water and extracted with 1-chlorobutane. After centrifugation, the organic phase was purified on conditioned silica minicolumns (LC-Si SPE columns, Varian, Les Ulis, France). E2 was derivatized with pentafluorobenzoyl chloride (103772-1G, Aldrich, Steinheim, Germany). The final extracts were reconstituted in isooctane and transferred into conical vial for injection into the GC system $(6890 \mathrm{~N}$, Agilent Technologies). A quadrupole mass spectrometer equipped with a chemical ionization source and operating in single ion monitoring mode was used for detection (HP5973, Agilent Technologies). The linearity of steroid measurement was confirmed by plotting the ratio of the E2 peak response/internal standard peak response to the concentration of E2 for calibration standard. Lower limit of quantification was $1.15 \mathrm{pg}$. The intra- and inter-assay variability of low limit of quantification CVs was $13.3-20 \%$.

\section{Statistical analyses}

Experiments were performed from at least four different samples per age/treatment group and data were analyzed by Prism 6 (version 6.0, GraphPad Software). Statistical analyses used Student $t$-test (comparison of two groups) or one-way ANOVA (>two groups) when data showed normal distribution as assessed by the Shapiro-Wilk test,

(C) 2019 Society for Endocrinology Published by Bioscientifica Ltd. Printed in Great Britain and if they did not pass this test, with a Kruskal-Wallis non-parametric test. Data are shown as means \pm s.E.M. A $P$ value $<0.05$ was considered as significant.

\section{Results}

High Amh expression in the prepubertal ovary, with a transient downregulation in preantral/early antral follicles of the first waves

Ontogenesis analysis of the relative intra-ovarian abundance of $A m h$ mRNA was monitored at different ages in infantile (7-21dpn), juvenile ( $27 \mathrm{dpn})$ and in adult cycling females (Fig. 1A). Amh mRNA levels progressively increased during the infantile period to become maximal between 14 and $21 \mathrm{dpn}$. It was then $\sim 2-3$-fold higher than that in adult females during reproductive life (Fig. 1A). We also studied AMH expression by Western blot (Fig. 1B). $\mathrm{AMH}$ is synthetized as a homodimeric glycoprotein (AMH precursor, $140 \mathrm{kDa}$ ) cleaved into a $25-\mathrm{kDa}$ C-terminal dimer and a $110-\mathrm{kDa} \mathrm{N}$-terminal dimer, which remain associated as a non-covalent complex (cleaved AMH) (di Clemente et al. 2010). Using an antibody recognizing AMH precursor form, we observed an expected band at $\sim 70 \mathrm{kDa}$ under reducing conditions (Fig. 1B). Although these data are qualitative, a similar trend as that for mRNA was observed for the protein. To determine whether prepubertal Amh synthesis resulted in detectable circulating AMH levels, we monitored serum AMH levels in females during the infantile and juvenile periods, as well as in adult cycling females at different stages of the estrus cycle (P, proestrus, E, estrus; D, diestrus) (Fig. 1C). There was no correlation between intra-ovarian Amh transcript and protein abundance and AMH serum levels. Indeed, circulating AMH levels were very low at $7 \mathrm{dpn}$, and they progressively increased during the infantile and juvenile periods. Notably, circulating AMH levels were $\sim 2-3$ fold more elevated in late infantile $(17,21 \mathrm{dpn})$ and juvenile females ( $27 \mathrm{dpn}$ ) than in adult cycling females (Fig. 1C). 
A

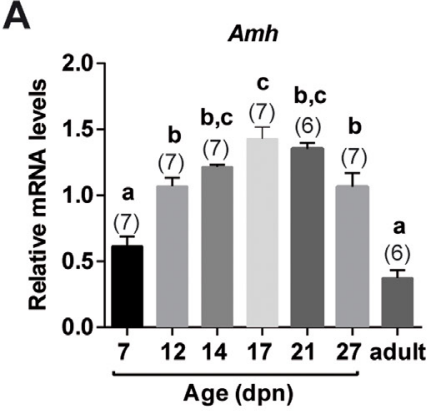

B

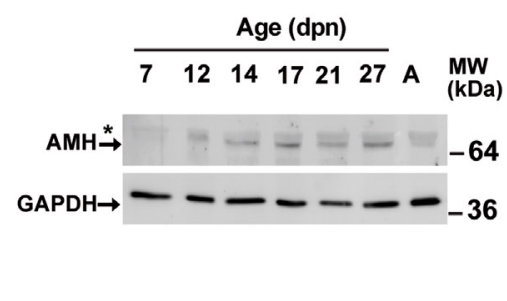

C

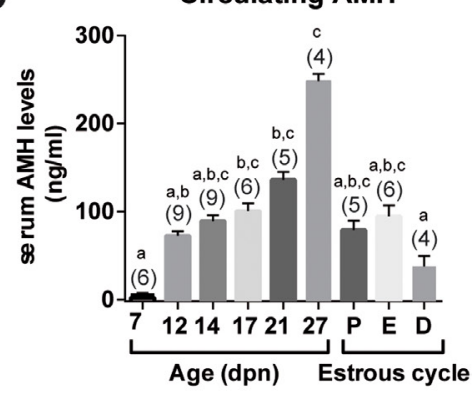

D

Age (dpn)

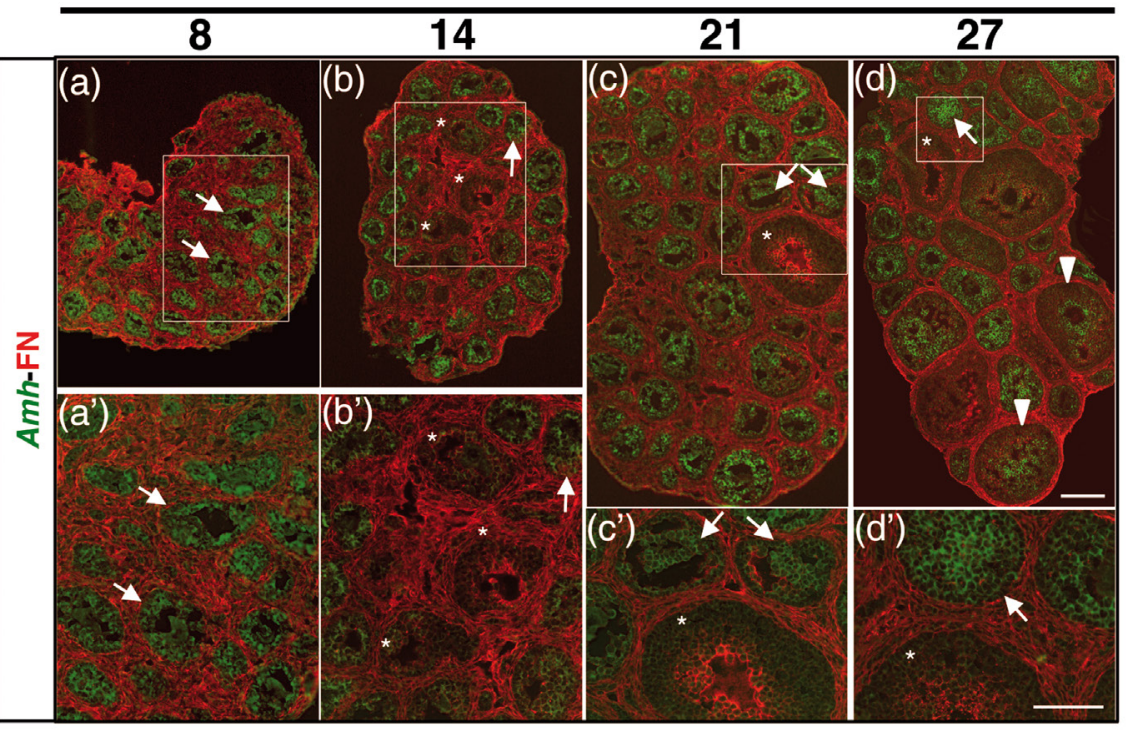

E

Age (dpn)

14

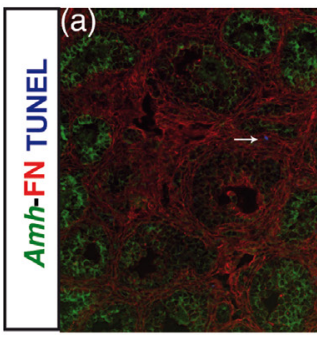

21

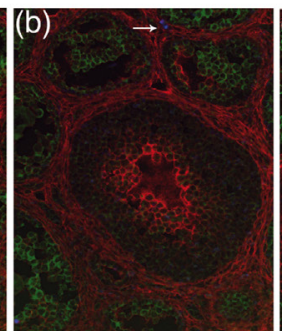

27

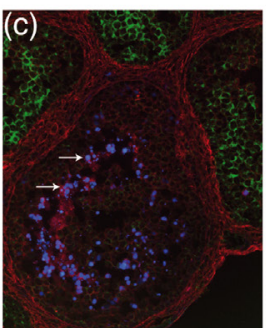

27

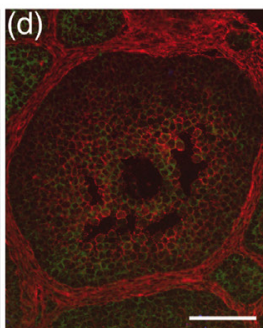

\section{Figure 1}

Ontogenesis of AMH expression in prepubertal female mice. (A) The relative intra-ovarian abundance of Amh transcripts in infantile (7-21 dpn), juvenile ( $27 \mathrm{dpn}$ ) and adult cycling females was determined by quantitative real-time RT-PCR and normalized to the mRNA levels of Hprt. The number of samples is indicated under parentheses. (B) AMH protein expression was analyzed in immature (7-27 dpn) and adult (A) ovaries by Western blot, with GAPDH used as a loading control. Representative immunoblots are shown. The star shows a non-specific upper band. (C) Serum AMH levels were measured by ELISA assay during the infantile (7-21 dpn) and the juvenile periods ( $27 \mathrm{dpn}$ ), and in adult cycling females (P, proestrus; $E$, estrus; $D$, diestrus) with the number of serum samples for each group shown under parentheses. (D) In situ hybridization with Amh probes (purple color digitally converted into green) and detection of fibronectin by immunofluorescence (red color) showing the distribution of Amh transcripts in the ovary during the infantile $(8,14$ and $21 \mathrm{dpn})$ and the juvenile periods ( $27 \mathrm{dpn})$. Pictures in $\mathrm{a}^{\prime}, \mathrm{b}^{\prime}, \mathrm{c}^{\prime}$ and $\mathrm{d}^{\prime}$ are enlargement of the rectangles located on pictures a, b, c and d, respectively. Arrows show Amh-positive preantral/early antral follicles, whereas stars show Amh-negative preantral/antral or medium/large antral follicles. Triangles show large antral follicles expressing Amh in cumulus cells. Due to the large size of the ovaries at 21 and $27 \mathrm{dpn}$, the pictures in c and d are reconstitution obtained from microphotographs taken in different parts of the same ovarian section. (E) Co-detection of apoptotic cells by TUNEL assay (green color digitally converted into blue), Amh transcripts by in situ hybridization (purple color digitally converted into green) and fibronectin by immunofluorescence (red color) at 14 (a), 21 (b) and 27 (c and d) dpn. Arrows show apoptotic cells located either outside (a, b) or inside (c) follicles. In graphs, bars are the means \pm S.E.M. Data were analyzed by one-way ANOVA (A) or Kruskal-Wallis (C) tests. Distinct letters indicate significant differences between ages. In (D) and (E), scale bars: $100 \mu \mathrm{m}$. 
During the prepubertal period, the ovary is endowed by primordial follicles and by growing follicles at different stages of development. There is a clear regionalization of these different categories of follicles during the neonatal and infantile periods: the most mature follicles, i.e., the first follicular waves, are present in the center, whereas subsequent waves and primordial follicles are located in the periphery (Guigon et al. 2003, Mork et al. 2012, Zheng et al. 2014). These two populations of growing follicles exhibit distinct functional characteristics (Guigon et al. 2003, François et al. 2017) and emerge from different granulosa cell lineage (Mork et al. 2012, Zheng et al. 2014). To closely monitor Amh ontogenesis in these two populations, we performed in situ hybridization (ISH) studies in infantile (8-21dpn) and juvenile (27dpn) females. At $8 \mathrm{dpn}, \mathrm{Amh}$ was expressed in granulosa cells of all growing follicles present, from the primary to the preantral stage (Fig. 1Da and inset in a'). Notably, at $14 \mathrm{dpn}$, Amh expression became low in the most mature follicles of the first waves, then reaching the preantral/ early antral stage (Fig. 1Db and inset in $\mathrm{b}^{\prime}$ ). Its expression was restricted to growing follicles present in the ovarian periphery (Fig. $1 \mathrm{Db}$ and inset in $\mathrm{b}^{\prime}$ ). In contrast, in older infantile ( $21 \mathrm{dpn}$ ) and juvenile females ( $27 \mathrm{dpn}), A m h$ was abundantly expressed in preantral/early antral follicles, including in those located in the center (Fig. 1Dc, d, and insets in $c^{\prime}$ and $d^{\prime}$, respectively). It was absent in mural granulosa cells from follicles at the medium and large antral stages, but still expressed in cumulus cells, as reported (Fig. 1Dc, d) (Baarends et al. 1995). To determine whether the observed transient Amh downregulation in preantral/early antral follicles at $14 \mathrm{dpn}$ could result from follicular atresia, we monitored granulosa cell apoptosis by TUNEL assay on the same tissue sections as those used for ISH. We could establish that at $14 \mathrm{dpn}$, preantral/early antral follicles with low Amh expression had no apoptotic granulosa cells (Fig. 1Ea). In contrast, a subset of medium to large antral follicles in late infantile and juvenile females with low Amh expression exhibited apoptotic granulosa cells, while others did not, as expected (Baarends et al. 1995) (Fig. 1Eb-d).

\section{FSH-induced downregulation of Amh expression in preantral/early antral follicles of the first follicular waves}

FSH can regulate AMH expression either positively or negatively in granulosa cells, depending on follicular stage, species and experimental approaches (Baarends et al. 1995, Taieb et al. 2011, Hardy et al. 2016, Roy et al. 2018).
From our ontogenesis studies, no clear relationship could be observed during the prebubertal period between circulating FSH levels becoming maximal at $12-14$ dpn (François et al. 2017) and either serum AMH levels or intraovarian Amh mRNA and protein abundance (Fig. 1A, B and C). However, the observation that the transient loss in Amh expression in preantral/early antral follicles occurs at the time when serum FSH levels become markedly elevated led us to determine whether FSH could be involved in the regulation of Amh expression in these follicles. For that purpose, we treated female mice with the GnRH receptor antagonist Ganirelix to decrease gonadotropin levels between 12 and $14 \mathrm{dpn}$. With this protocol, there is a reduction by $\sim 80 \%$ for FSH and by $\sim 95 \%$ of $\mathrm{LH}$ levels (François et al. 2017). Some of these mice were supplemented with the exogenous gonadotropin eCG that exhibits pronounced FSH activity in rodents (Combarnous et al. 1984) (Fig. 2A). We recently demonstrated that these treatments do not alter the number and the size of growing follicles (François et al. 2017), and hence, they probably do not affect ovarian cellular composition. Ganirelix treatment induced a $\sim 2$-fold decrease in relative mRNA abundance of $F s h r$, as previously observed for two other FSH-regulated genes, i.e., Cyp19a1 and Ccnd2 mRNA. This effect was partially reverted by eCG co-administration (Fig. 2B). Notably, analyses of Amh mRNA by real-time RT-PCR revealed that Ganirelix induced a significant increase by $\sim 30 \%$ in their relative intra-ovarian levels; this increase was prevented by the co-administration of eCG (Fig. 2C). In situ examination of Amh expression pattern in the ovary showed that Ganirelix treatment clearly restored Amh expression in preantral/small antral follicles located in the core of the ovary, whereas co-treatment with eCG prevented it (Fig. 2D, areas outlined by dotted lines).

To further specify the effect of FSH on the expression of Amh, we used an ex vivo culture system (Fig. 2E). Ovaries from 12-dpn mice were cultured in serum-free medium, and then treated for $8 \mathrm{~h}$ with different concentrations of purified FSH (50, 200 and 500 ng/mL) (Fig. 2E). In control conditions (no FSH), Fshr transcripts were detected in the ovary; their relative abundance increased by $\sim 2$-fold following treatment with the highest used FSH concentration mimicking the elevated infantile levels (Fig. 2F). Importantly, FSH induced a dose-dependent decrease in Amh mRNA levels that became substantial at the highest used concentration (Fig. 2G). No apparent change in preantral/early antral follicle size was observed between control and FSH-treated group, as expected for a short-term treatment (Fig. 2H). It is therefore unlikely that the observed alterations in gene expression result from a change in ovarian cellular composition. 


\begin{tabular}{l|l|l|r|r|}
$\begin{array}{l}\text { Journal of } \\
\text { Endocrinology }\end{array}$ & M Devillers et al. & $\begin{array}{l}\text { FSH and AMH interplay in the } \\
\text { infantile ovary }\end{array}$ & $240: 2$ & 221 \\
\hline
\end{tabular}

A
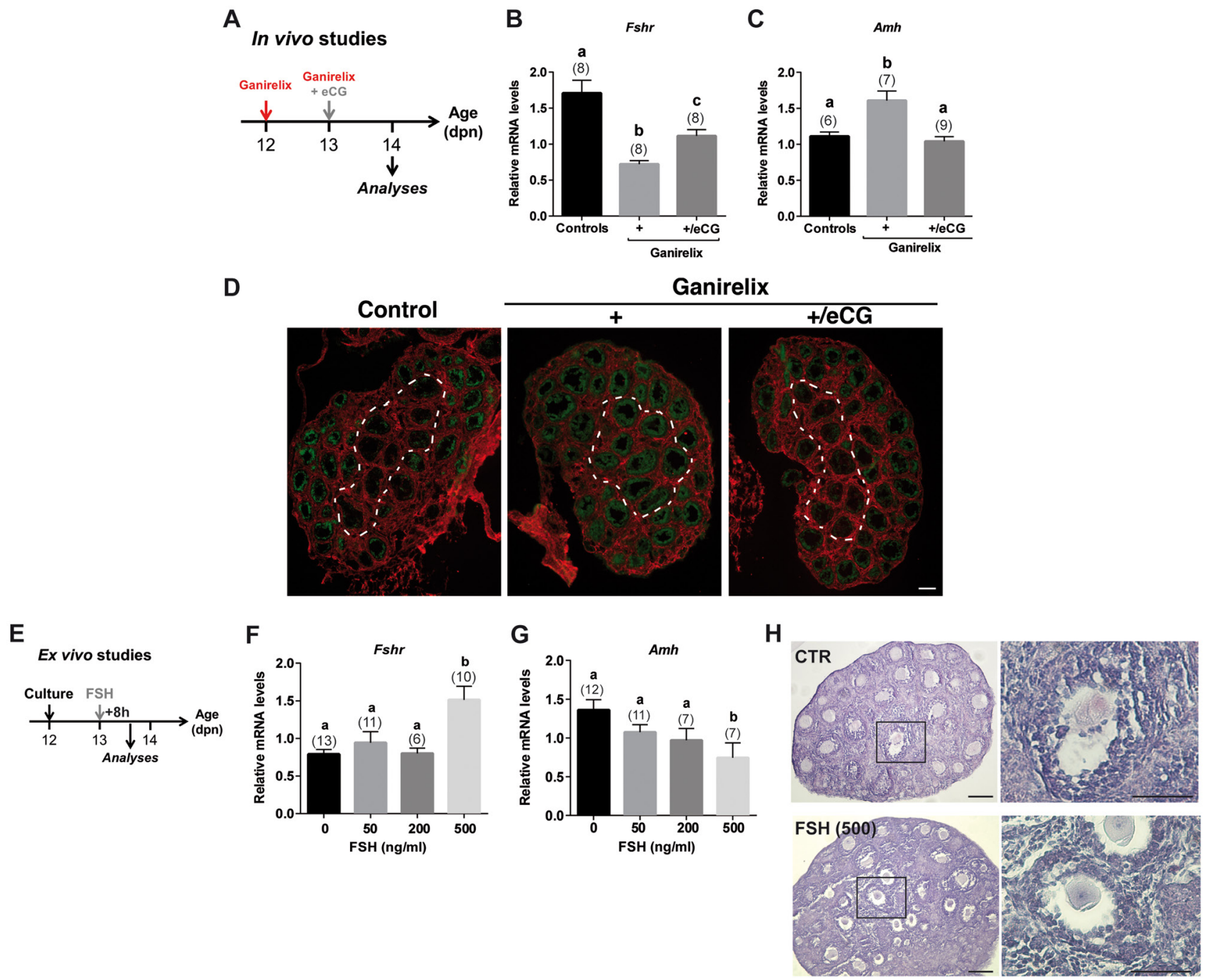

Figure 2

High FSH concentrations repress Amh expression in the first follicular waves. (A) Schematic representation of the procedure used to experimentally manipulate FSH levels between 12 and $14 \mathrm{dpn}$ in mice. (B) Relative intra-ovarian contents of Fshr mRNA in the ovaries of infantile females treated with saline (controls), Ganirelix (+) or Ganirelix + eCG (+/eCG) determined by quantitative real-time RT-PCR after normalization by the levels of Hprt mRNAs. The number of used samples is indicated under parentheses. (C) Relative intra-ovarian contents of Amh mRNA in the ovaries of infantile females treated with saline (controls), Ganirelix (+) or Ganirelix + eCG (+/eCG) determined by quantitative real-time RT-PCR after normalization by the levels of Hprt mRNAs. The number of used samples is indicated under parentheses. (D) Distribution pattern of Amh mRNA by in situ hybridization with specific probes (purple color digitally converted into green) and fibronectin immunofluorescence (red color) in the ovaries of control or Ganirelix-treated mice supplemented or not with eCG in vivo. The area containing follicles of the first follicular waves is delimited by dotted lines. (E) Schematic representation of the procedure used for ovarian culture. (F) Effect of increasing FSH concentrations (50-500 ng/mL) on the relative intra-ovarian levels of Fshr mRNA in organotypic culture. Data were obtained by quantitative real-time RT-PCR and normalized by the levels of Hprt mRNAs. The number of used samples is indicated under parentheses. (G) Effect of increasing FSH concentrations (50-500 ng/mL) on the relative intra-ovarian levels of Amh mRNA in organotypic culture. Data were obtained by quantitative real-time RT-PCR and normalized by the levels of Hprt mRNAs. The number of used samples is indicated under parentheses. $(\mathrm{H})$ Representative histological sections of ovaries cultured in control (CTR) or FSH ( $500 \mathrm{ng} / \mathrm{mL})$-supplemented medium. Right panels show enlargement of the largest follicle seen on the left panels. In graphs, bars are the means \pm S.E.M. Data were analyzed by one-way ANOVA (B and G) or Kruskal-Wallis (C and F) tests. Distinct letters indicate significant differences between ages. In (D) and (H), scale bars: $100 \mu \mathrm{m}$.

\section{FSH repressive action on Amh expression in} preantral/early antral follicles is not mediated by estradiol

FSH stimulates the production of E2, which in turn would suppress Amh expression through estrogen receptor $\beta$ (ER $\beta)$ in vitro, as shown in luteinized or tumoral granulosa cells (Grynberg et al. 2012). In infantile mice, we previously showed that the increased levels of FSH induced a significant elevation in serum E2 levels (François et al. 2017). Thus, we next sought to investigate whether FSH-induced repression of Amh expression observed in 
infantile ovaries could, in fact, rely on E2 action through $\mathrm{ER} \beta$, since this receptor is already expressed in growing follicles of the immature mouse ovary (Balla et al. 2003).

To analyze the possible involvement of $\mathrm{E} 2$, we took advantage of the infantile Ganirelix-treated mouse model, which displays a $\sim 2$-fold decrease in E2 serum levels (François et al. 2017). We first measured the intra-ovarian E2 contents in both groups to determine the appropriate amount of E2 to administer to Ganirelix-treated females to restore E2 levels close to those of control females. The observed quantity (controls: $5.54 \pm 0.94 \mathrm{pg} / \mathrm{ovary}$ vs Ganirelix: $1.36 \pm 0.39 \mathrm{pg} /$ ovary, $n=6-7$ ovaries/group, $P<0.01)$ led us to administer $8 \mathrm{pg} /$ female, following the schedule shown in Fig. 3A. This amount of E2 efficiently increased uterus weights in Ganirelix-treated mice as compared with the two other groups (Fig. 3B). We then analyzed the relative intra-ovarian Amh expression by both quantitative and in situ approaches. Notably, Amh transcript levels in Ganirelix-treated females were not altered by E2, and they remained higher than in control females (Fig. 3C). In line with these findings, preantral/ early antral follicles in the center of the ovary maintained Amh expression in Ganirelix-treated females despite E2 treatment (Fig. 3D, virtual area outlined by dotted lines). Thus, FSH may directly regulate Amh expression, without implying estrogen signaling at this stage of development.

To determine whether the lack of E2 action on Amh expression results from the relative insensitivity of those follicles to E2, we performed a small-scale analyses of documented E2 target genes in granulosa cells of growing follicles, i.e., Cyp19a1, Foxo1 (Forkhead box protein 1) and Glut-1 (Glucose transporter 1) (Richards et al. 2002). Surprisingly, none of the studied genes exhibited alterations in their expression levels following E2 treatment in Ganirelix-treated females as compared with those administered with Ganirelix alone (Fig. 3E). These findings suggest that the ovary would not be sensitive to E2 during the infantile period.

\section{AMH prevents FSH-mediated induction of Cyp19a1 aromatase without altering Fshr and Ccnd2 expression in the infantile ovary}

The present study reveals that FSH represses Amh expression specifically in the first follicular waves, wherein we previously showed that FSH induces a consistent Cyp19a1 aromatase expression without altering that of Ccnd2 (François et al. 2017). Since other studies reported that AMH prevents FSH-induced E2 synthesis (Grossman et al. 2008, Chang et al. 2013, Prapa et al. 2015,
Sacchi et al. 2016), possibly by down-regulating FSHR expression (Pellatt et al. 2011), and that it regulates FSH-mediated follicular growth (McGee et al. 1997, Durlinger et al. 2001), we next sought to investigate whether the observed decrease in Amh expression could facilitate FSH-mediated Cyp19a1 expression and explain the loss of FSH-mediated Ccnd2 expression in preantral/early antral follicles. We therefore tested the effect of a treatment by AMH on the expression of Cyp19a1, Fshr and Ccnd2 in the infantile ovary. We used an ex vivo culture system instead of administering AMH in vivo, since we and others have reported the occurrence of extra-gonadal actions of AMH that could increase both LH and FSH levels, thereby indirectly altering ovarian function (Cimino et al. 2016, Garrel et al. 2016). We cultured infantile ovaries from mice aged $12 \mathrm{dpn}$ with either FSH $(500 \mathrm{ng} / \mathrm{mL})$ or AMH alone or combined, for $8 \mathrm{~h}$ (Fig. 4A). Histological analyses of ovarian explants showed no visible alteration in the size of preantral/early antral follicles (shown for FSH and $\mathrm{FSH}+\mathrm{AMH}$ treatment in Fig. 4B). We then determined the relative abundance of Cyp19a1, Fshr and Ccnd2 mRNA. Under these experimental conditions, treatment with AMH alone had no significant effect on either basal Cyp19a1, Fshr or Ccnd2 expression levels (Fig. 4Ca-c). FSH significantly upregulated Cyp19a1 and Fshr mRNA levels, while it had no effect on those of Ccnd2, as reported before (François et al. 2017) (Fig. 4Ca-c). Notably, in the presence of AMH, FSH did not induce Cyp19a1 expression, which remained at basal levels (Fig. 4Ca). This inhibitory effect of AMH on FSH action occurred in the absence of alterations in Fshr mRNA levels (Fig. 4Cb). Similarly, AMH did not alter the relative abundance of Ccnd2 mRNAs in the presence of FSH (Fig. 4Cc). Western blot analyses of Cyclin D2 and aromatase proteins recapitulated the findings obtained on their mRNA levels (Fig. 4D).

\section{Discussion}

AMH plays a critical role in regulating ovarian function during reproductive life, in particular by limiting FSH actions in small growing follicles to prevent their premature maturation (reviewed in (Visser \& Themmen 2014)). This study is, to our knowledge, the first to investigate the interplay between AMH and FSH on the regulation of the infantile ovarian function. Because the infantile ovary is relatively easy to maintain in ex vivo culture, this experimental model provided us with the opportunity to decipher in a better physiological context than in luteinized or in tumoral granulosa cell cultures, 


\begin{tabular}{l|l|l|l|l|}
$\begin{array}{l}\text { Journal of } \\
\text { Endocrinology }\end{array}$ & M Devillers et al. & $\begin{array}{l}\text { FSH and AMH interplay in the } \\
\text { infantile ovary }\end{array}$ & $240: 2$ & 223 \\
\hline
\end{tabular}

A

\section{In vivo studies}

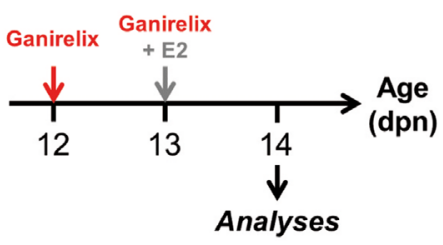

D
B

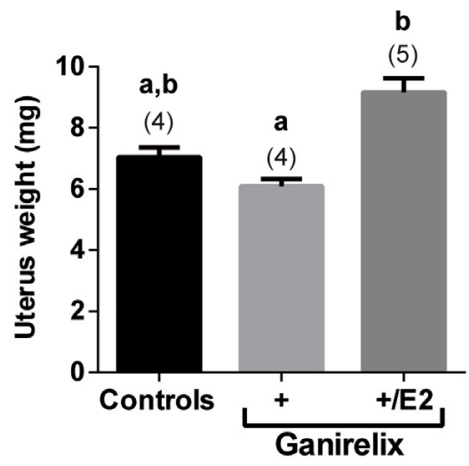

C

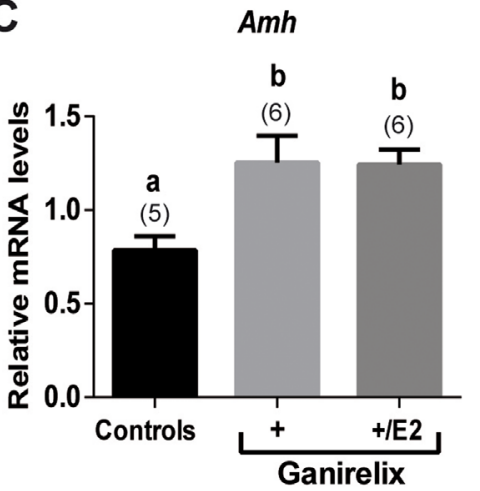

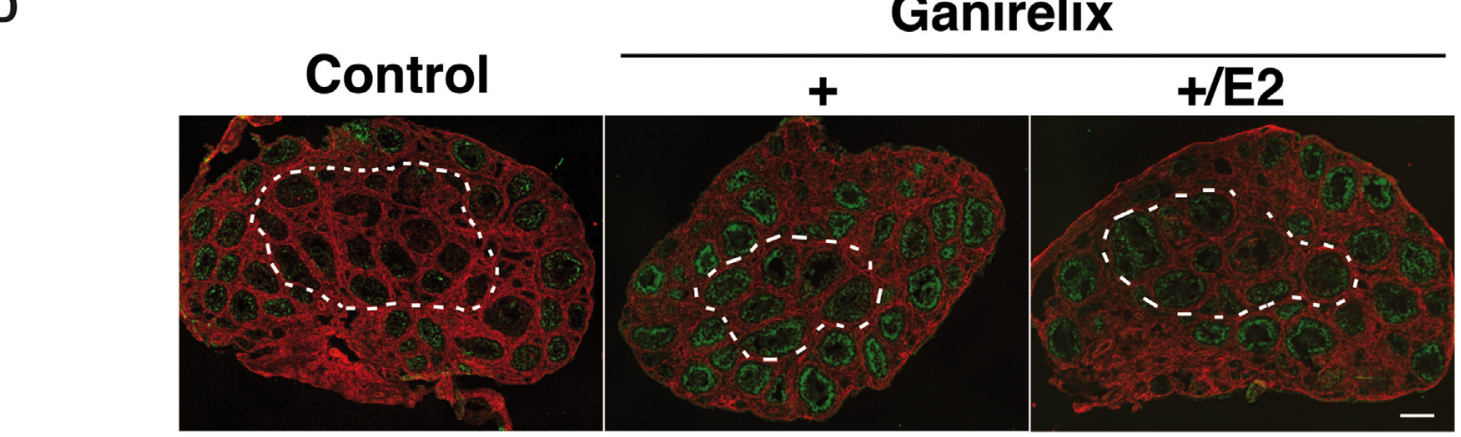

E
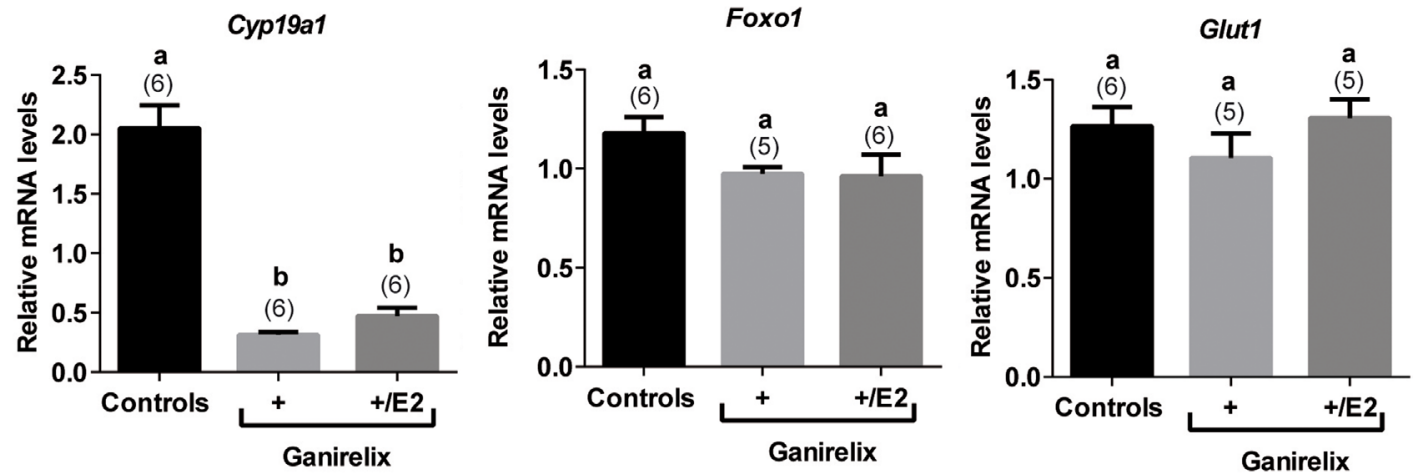

Figure 3

Estradiol does not repress Amh expression in infantile ovaries. (A) Schematic representation of the procedure used to experimentally alter E2 levels between 12 and 14 dpn in mice. (B) Uterus weights in controls, Ganirelix (+) and Ganirelix + E2-treated (+/E2) female mice. The number of samples for each group is shown under parentheses. (C) Relative intra-ovarian abundance of Amh transcripts in controls, Ganirelix (+) and Ganirelix + E2-treated (+/E2) female mice determined by quantitative real-time RT-PCR after normalization by the levels of Hprt mRNAs. The number of samples for each group is shown under parentheses. (D) Distribution pattern of Amh mRNA by in situ hybridization with specific probes (purple color digitally converted into green) and fibronectin immunofluorescence (red color) in the ovaries of control or Ganirelix-treated mice supplemented or not with estradiol (E2) in vivo. The area containing follicles of the first follicular waves is delimited by dotted lines. (E) Relative intra-ovarian abundance of E2-target genes, i.e., Cyp19a1, Foxo1 and Glut1 transcripts, in controls, Ganirelix (+) and Ganirelix + E2-treated (+/E2) female mice, determined by quantitative real-time RT-PCR after normalization by the levels of Hprt mRNAs. The number of samples for each group is shown under parentheses. In graphs, bars are the means \pm S.E.M. Data in $(B),(C)$, and $(E)$ were analyzed by Kruskal-Wallis non-parametric test, with distinct letters indicating significant differences between groups $(P<0.05)$. In (D), scale bars: $100 \mu \mathrm{m}$.

the effect of FSH on AMH expression on the one hand, and the action of AMH on FSH-induced regulation on the other hand. We used a complementary approach in vivo in the mouse in which gonadotropin levels can be easily manipulated during the infantile period (François et al. 2017). Remarkably, our data demonstrate the existence of a repressive action of FSH on Amh expression in preantral/early antral follicles of the first follicular waves. As the main suppliers of E2 during the infantile period, these follicles may play a critical role in the programming of adult reproductive function. Our data support the idea that this action of FSH on Amh expression is necessary to 
A

Ex vivo studies

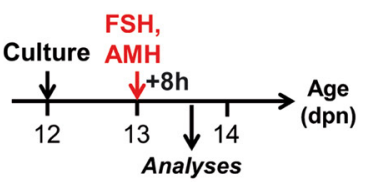

C

(a)

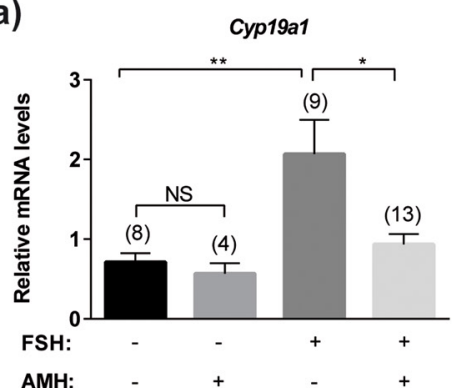

(c)

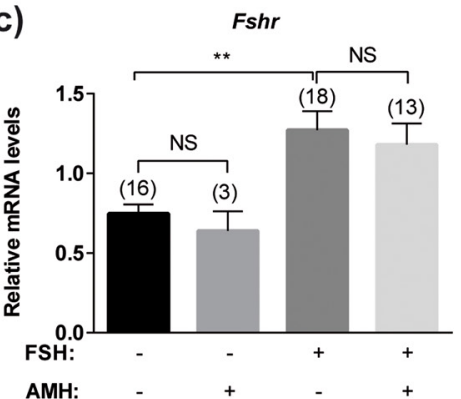

B
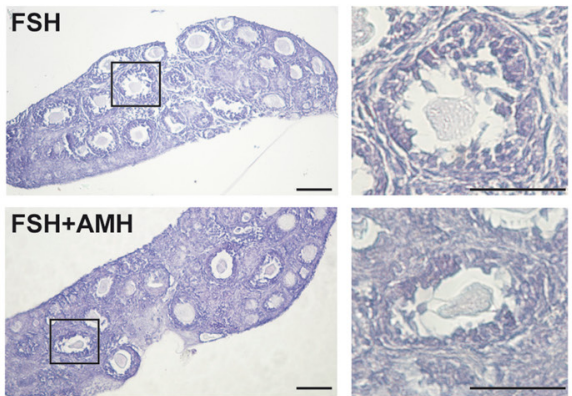

(b)

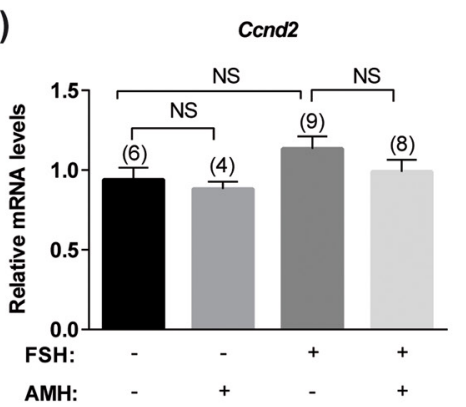

D

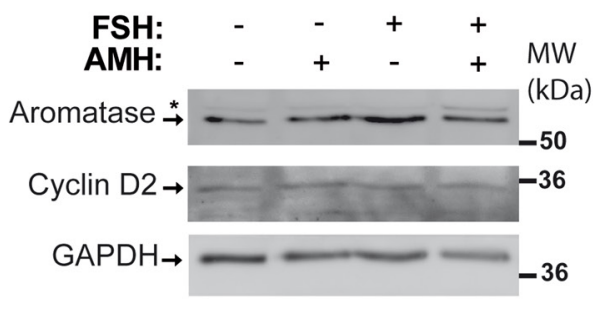

\section{Figure 4}

AMH represses the relative abundance of Cyp19a1 mRNA but not that of either Fshr or Ccnd2. (A) Schematic representation of the procedure used for ovarian culture. (B) Representative histological sections of ovaries cultured in FSH ( $500 \mathrm{ng} / \mathrm{mL}$ ) or FSH+AMH-supplemented medium. The right panels show enlarged magnification of the largest follicles seen on the left panels. Scale bars: $100 \mu \mathrm{m}$. (C) Effect of FSH $(500 \mathrm{ng} / \mathrm{mL})$ and $\mathrm{AMH}(400 \mathrm{ng} / \mathrm{mL})$ alone or combined, on Cyp19a1 (a), Ccnd2 (b), and Fshr (c) mRNA levels in cultured ovaries. Transcript levels were analyzed by quantitative real-time RT-PCR, and normalized by those of Hprt mRNAs. The number of samples for each group is shown under parentheses. (D) Aromatase and Cyclin D2 protein expression was analyzed in ovarian explants by Western blot, with GAPDH used as a loading control. Representative immunoblots are shown. The star shows an upper non-specific band. In graphs, bars are the means \pm s.E.M. Data were analyzed by Kruskal-Wallis non-parametric test with *, $P<0.05 ; * *, P<0.01$. NS, not significant. alleviate the inhibitory action of AMH on FSH-dependent E2 biosynthesis in these growing follicles (Fig. 5).

Our in situ studies highlight the fact that Amh displays a marked alteration in its expression pattern during the prepubertal period. Indeed, initially expressed in all growing follicles at the very beginning of the infantile period, Amh was subsequently downregulated in preantral/early antral follicles of the first waves at $\sim 14 \mathrm{dpn}$. This decrease did not result from follicular atresia, since granulosa cell apoptosis was still marginal at this age. In older prepubertal females, Amh expression was again observed in preantral/early antral follicles, and it was downregulated in (healthy or atretic) medium to large antral follicles, as described by others (Baarends et al. 1995). The observation that Amh downregulation in preantral/early antral follicles of the first waves occurred concomitantly to the dramatic rise in FSH levels in infantile females prompted us to test the hypothesis that FSH represses Amh expression in these follicles despite their relative immaturity. In our studies, in vivo manipulation of gonadotropin levels in infantile mice strongly suggests that it would be the case. Further supporting this hypothesis, our ex vivo studies indicated that FSH dose-dependently repressed Amh expression in the infantile ovary. In line with our findings, a previous report suggested that administration of FSH to juvenile rats decreases Amh expression in preantral/early antral follicles, albeit this effect has not been quantified (Baarends et al. 1995). In addition, in vitro studies on cultured preantral follicles collected from infantile mice reported that FSH induces Amh downregulation (Hardy et al. 2016). In adult and juvenile ovaries, the expression of AMH disappears from mural granulosa cells at the antral stage, when the follicle supposedly requires FSH for its subsequent growth and maturation. The role played by the oocyte-derived factors GDF9 and BMP15 on FSHmediated repression of $A m h$ has been recently highlighted in mouse primary cultures of granulosa cells and in the tumor-derived granulosa KGN cell line (Roy et al. 2018). This study indicates that Amh expression implies a tight dialog between granulosa cells and the oocyte. It could also 


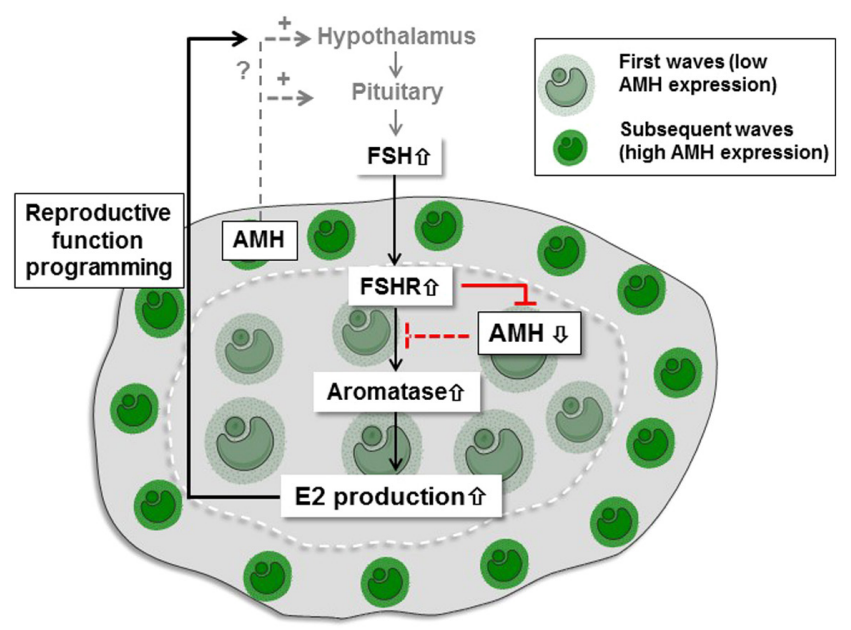

\section{Figure 5}

Proposed model for the regulatory loop between FSH and AMH during the infantile period in the mouse. The high FSH levels would enhance $\mathrm{FSH}$ receptivity in preantral/small antral follicles of the first waves located in the center of the ovary, and decrease their expression of Amh. The loss of Amh expression in these follicles may facilitate $\mathrm{FSH}$-induction of Cyp19a1 aromatase and thus the synthesis of E2 that is required for programming adult reproductive function. The production of $\mathrm{AMH}$ by subsequent follicular waves located in the ovarian periphery may target the hypothalamus and the pituitary (Cimino et al. 2016, Garrel et al. 2016) to increase $\mathrm{LH}$ and $\mathrm{FSH}$ levels, thereby leading to increased ovarian activity (see text for more explanations). A full-colour version of this figure is available at https://doi.org/10.1530/JOE-18-0313.

explain the opposite findings about FSH regulation of Amh expression, and warn about culture conditions and experimental models.

The occurrence of FSH-induced Amh downregulation in follicles at an earlier developmental stage in the infantile ovary than in older females suggests a precocious acquisition of FSH receptivity in growing follicles of immature females. FSHR starts to be expressed in the mouse ovary as soon as the neonatal period (O'Shaughnessy et al. 1997). Cultured infantile preantral/early antral follicles display Fshr expression and are responsive to FSH in terms of steroidogenesis-related gene induction (Hardy et al. 2016). The apparent lack of FSH-mediated repression of Amh expression in growing follicles from the ovarian periphery may reflect their low receptivity to FSH, as suggested by others (Hardy et al. 2016). We report here that FSH stimulates the expression of its own receptor in the infantile ovary, as previously suggested (O'Shaughnessy et al. 1997). Thus, the high FSH levels of the infantile period may well boost FSH receptivity specifically in the first follicular waves, thereby leading to the premature extinction of Amh expression in growing follicles despite their early stage of development. Whether high levels of FSH would have the same effect in the adult ovary remains to be investigated. In favor of this hypothesis, however, the expression of Amh is downregulated in preantral follicles specifically at the estrus stage (Baarends et al. 1995), i.e., right after the cyclic elevations in FSH levels.

We presently do not know the molecular mechanisms whereby FSH downregulates Amh expression in the infantile ovary. Since FSH stimulates E2 production, a few studies have proposed that this effect of FSH could be mediated by E2 (Baarends et al. 1995, Grynberg et al. 2012). Furthermore, in vitro studies have shown that it would imply ER $\beta$ binding to an estrogen response element in the $A M H$ promoter (Grynberg et al. 2012). Despite ER $\beta$ expression and significant E2 production in the infantile ovary (Balla et al. 2003, François et al. 2017), our experiments provide some evidence that E2 has, by itself, no effect on Amh expression in preantral/early antral follicles during this period. This contrasts with results obtained in juvenile rats, wherein exogenous E2 treatment could downregulate Amh expression in preantral/early antral follicles (Baarends et al. 1995). Together with our observations that E2 has no effect on a subset of known E2 target genes in the infantile ovary, our study raises the intriguing possibility that E2 signaling may be inactive in preantral/early antral follicles during this period. Whether the peculiar endocrine environment of the infantile period underlie this feature should be investigated in the future. FSH may, thus, be a direct regulator of Amh expression in these follicles. The possibility that it involves FSH-mediated activation of the canonical cAMP/ protein kinase A (PKA) pathway to regulate Amh promoter activity is supported by a recent study in primary cultures of mouse granulosa cells and in KGN cells (Roy et al. 2018).

In the infantile ovary, our findings showed that AMH treatment significantly repressed FSH-mediated induction of Cyp19a1 aromatase, as previously described for human luteinized granulosa cells in vitro (Grossman et al. 2008, Chang et al. 2013, Prapa et al. 2015, Sacchi et al. 2016). This effect unlikely resulted from decreased FSHR expression as described in human tumoral granulosa cells (Pellatt et al. 2011), since AMH did not alter Fshr transcript abundance, albeit we cannot exclude that it could have affected FSHR protein levels. However, one can hypothesize that AMH could inhibit FSH-stimulated adenylyl cyclase activity, as described in human granulosa cells in vitro (Chang et al. 2013). Amh abundance was low in preantral/early antral follicles of the first waves, which express Cyp19a1 aromatase (François et al. 2017). In contrast, Amh expression was high in growing follicles of the subsequent waves, wherein there is little Cyp19a1 
expression (François et al. 2017). Hence, we hypothesize that FSH-induced repression of Amh in preantral/early antral follicles of the first waves contributes to FSH induction of E2 production in these follicles. In contrast, although $\mathrm{AMH}$ regulates the growth of follicles in vivo and in vitro (McGee et al. 1997, Durlinger et al. 2001), we did not observe any effect of AMH on Ccnd2 expression in infantile ovaries, in the presence or not of FSH. We previously reported that at high levels, FSH could not induce granulosa cell expression of $C c n d 2$ and granulosa cell proliferation (François et al. 2017). These findings suggest that the lack of FSH action on the growth of the first follicular waves during the infantile period does not rely on Amh loss in these follicles. Future studies are warranted to understand how high FSH levels lead to the loss of FSH-mediated induction of Ccnd2 induction and granulosa cell proliferation.

The consistent elevation in the relative levels of intraovarian Amh transcript and protein abundance during the infantile period correlates with the previously reported large number of growing follicles as compared with the adult (Pedersen 1969). This profile in intra-ovarian $\mathrm{AMH}$ abundance contrasted with that of circulating $\mathrm{AMH}$, which showed a progressive increase during the infantile period to become dramatically elevated in juvenile females. While the reason behind this apparent discrepancy between intra-ovarian and circulating AMH levels is not clear at present, it may simply result from changes in ovarian cellular composition, with juvenile ovaries producing more AMH because of the overall increase in the number of granulosa cells in large antral follicles (Jeppesen et al. 2013).

The significant production of AMH by the prepubertal ovary and its detection in the serum raises the point as to whether ovarian AMH could target newly identified extra-gonadal sites, i.e., the hypothalamus and the pituitary (Cimino et al. 2016, Garrel et al. 2016). In the hypothalamus, AMH binds to its receptor, AMHRII, to activate GnRH neuron activity, and thereby it stimulates LH secretion in vivo in the mouse (Cimino et al. 2016). In the pituitary, AMH binds to AMHRII to increase FSH synthesis and secretion, specifically during the infantile period in the female rat (Garrel et al. 2016). It would be of interest to specify the contribution of ovarian AMH to the transient increase in both GnRH neuron activity and gonadotropin levels observed during the infantile period (Dulka \& Moenter 2017, François et al. 2017).

In conclusion, the present work leads us to propose that the high levels of gonadotropin hormones during the infantile period prematurely sensitize the first follicular waves to the action of FSH (Fig. 5). FSH stimulates Cyp19a1 aromatase expression in these follicles, an effect that may be facilitated by FSH-induced downregulation of Amh expression in these follicles (Fig. 5). In contrast, FSH may not act on subsequent follicular waves that still significantly express AMH. Together with recent reports on AMH actions in the hypothalamo-pituitary system (Cimino et al. 2016, Garrel et al. 2016), the present study highlights the idea that $\mathrm{AMH}$ would exert both intraand extra-ovarian actions and thus be a major regulator of the gonadotrope axis in infantile mice. By eventually contributing to the production of high amounts of $\mathrm{E} 2$ in infantile females, AMH would therefore play an important role in reproductive function programming.

\section{Declaration of interest}

The authors declare that there is no conflict of interest that could be perceived as prejudicing the impartiality of the research reported.

\section{Funding}

This work was funded by 'Institut National de la Santé et de la Recherche Médicale' (Inserm), by ‘Centre National de la Recherche Scientifique' (CNRS), by University Paris Diderot, and by fellowships from Ecole Doctorale BioSPC (to C M F, V C and M D).

\section{Author contribution statement}

$M D, F P, V C, C M F, F G$ and $G G$ performed experiments. $M D$ and $C M$ $F$ prepared figures and analyzed the data. J C-T read the manuscript. C J G designed the project, analyzed data, prepared figures and wrote the manuscript.

\section{Acknowledgements}

The authors wish to thank Dr N Di Clemente, Dr C Racine and Dr A Pierre for their help in real-time RT-PCR on Amh, and David L'Hôte for providing Foxo1 real-time PCR primers. They also appreciated valuable discussions about $\mathrm{AMH}$ in the developing ovary with Dr S Magre. They acknowledge the great help of the technicians of the Buffon Animal Facility (University Paris Diderot, France).

\section{References}

Baarends WM, Uilenbroek JT, Kramer P, Hoogerbrugge JW, van Leeuwen EC, Themmen AP \& Grootegoed JA 1995 Anti-müllerian hormone and anti-müllerian hormone type II receptor messenger ribonucleic acid expression in rat ovaries during postnatal development, the estrous cycle, and gonadotropin-induced follicle growth. Endocrinology 136 4951-4962. (https://doi.org/10.1210/ endo.136.11.7588229)

Balla A, Danilovich N, Yang Y \& Sairam MR 2003 Dynamics of ovarian development in the FORKO immature mouse: structural and 
functional implications for ovarian reserve. Biology of Reproduction 69 1281-1293. (https://doi.org/10.1095/biolreprod.103.015552)

Brock O, Baum MJ \& Bakker J 2011 The development of female sexual behavior requires prepubertal estradiol. The Journal of Neuroscience 31 5574-5578. (https://doi.org/10.1523/JNEUROSCI.0209-11.2011)

Chang H-M, Klausen C \& Leung PCK 2013 Antimüllerian hormone inhibits follicle-stimulating hormone-induced adenylyl cyclase activation, aromatase expression, and estradiol production in human granulosa-lutein cells. Fertility and Sterility 100 585.e1-592.e1. (https://doi.org/10.1016/j.fertnstert.2013.04.019)

Chellakooty M, Schmidt IM, Haavisto AM, Boisen KA, Damgaard IN, Mau C, Petersen JH, Juul A, Skakkebaek NE \& Main KM 2003 Inhibin $\mathrm{A}$, inhibin $\mathrm{B}$, follicle-stimulating hormone, luteinizing hormone, estradiol, and sex hormone-binding globulin levels in 473 healthy infant girls. Journal of Clinical Endocrinology and Metabolism $\mathbf{8 8}$ 3515-3520. (https://doi.org/10.1210/jc.2002-021468)

Cimino I, Casoni F, Liu X, Messina A, Parkash J, Jamin SP, CatteauJonard S, Collier F, Baroncini M, Dewailly D, et al. 2016 Novel role for anti-Müllerian hormone in the regulation of GnRH neuron excitability and hormone secretion. Nature Communications 710055. (https://doi.org/10.1038/ncomms10055)

Clarkson J, Boon WC, Simpson ER \& Herbison AE 2009 Postnatal development of an estradiol-kisspeptin positive feedback mechanism implicated in puberty onset. Endocrinology 150 3214-3220. (https:// doi.org/10.1210/en.2008-1733)

di Clemente N, Jamin SP, Lugovskoy A, Carmillo P, Ehrenfels C, Picard JY, Whitty A, Josso N, Pepinsky RB \& Cate RL 2010 Processing of antimullerian hormone regulates receptor activation by a mechanism distinct from TGF-beta. Molecular Endocrinology 24 2193-2206. (https://doi.org/10.1210/me.2010-0273)

Combarnous Y, Guillou F \& Martinat N 1984 Comparison of in vitro follicle-stimulating hormone (FSH) activity of equine gonadotropins (luteinizing hormone, FSH, and chorionic gonadotropin) in male and female rats. Endocrinology 115 1821-1827. (https://doi.org/10.1210/ endo-115-5-1821)

Döhler KD \& Wuttke W 1975 Changes with age in levels of serum gonadotropins, prolactin and gonadal steroids in prepubertal male and female rats. Endocrinology 97 898-907. (https://doi.org/10.1210/ endo-97-4-898)

Dulka EA \& Moenter SM 2017 Prepubertal development of gonadotropinreleasing hormone neuron activity is altered by sex, age, and prenatal androgen exposure. Endocrinology 158 3943-3953. (https://doi. org/10.1210/en.2017-00768)

Dullaart J, Kent J \& Ryle M 1975 Serum gonadotrophin concentrations in infantile female mice. Journal of Reproduction and Fertility 43 189-192. (https://doi.org/10.1530/jrf.0.0430189)

Durlinger AL, Gruijters MJ, Kramer P, Karels B, Kumar TR, Matzuk MM, Rose UM, de Jong FH, Uilenbroek JT, Grootegoed JA, et al. 2001 Anti-Müllerian hormone attenuates the effects of FSH on follicle development in the mouse ovary. Endocrinology 142 4891-4899. (https://doi.org/10.1210/endo.142.11.8486)

Fortune JE \& Eppig JJ 1979 Effects of gonadotropins on steroid secretion by infantile and juvenile mouse ovaries in vitro. Endocrinology $\mathbf{1 0 5}$ 760-768. (https://doi.org/10.1210/endo-105-3-760)

François CM, Petit F, Giton F, Gougeon A, Ravel C, Magre S, CohenTannoudji J \& Guigon CJ 2017 A novel action of follicle-stimulating hormone in the ovary promotes estradiol production without inducing excessive follicular growth before puberty. Scientific Reports $\mathbf{7}$ 46222. (https://doi.org/10.1038/srep46222)

Garrel G, Racine C, L'Hôte D, Denoyelle C, Guigon CJ, di Clemente N \& Cohen-Tannoudji J 2016 Anti-Müllerian hormone: a new actor of sexual dimorphism in pituitary gonadotrope activity before puberty. Scientific Reports 6 23790. (https://doi.org/10.1038/ srep23790)

Grossman MP, Nakajima ST, Fallat ME \& Siow Y 2008 Müllerianinhibiting substance inhibits cytochrome $\mathrm{P} 450$ aromatase activity in human granulosa lutein cell culture. Fertility and Sterility $\mathbf{8 9}$ 1364-1370. (https://doi.org/10.1016/j.fertnstert.2007.03.066)

Grynberg M, Pierre A, Rey R, Leclerc A, Arouche N, Hesters L, CatteauJonard S, Frydman R, Picard J-Y, Fanchin R, et al. 2012 Differential regulation of ovarian anti-müllerian hormone (AMH) by estradiol through $\alpha$ - and $\beta$-estrogen receptors. Journal of Clinical Endocrinology and Metabolism 97 E1649-E1657. (https://doi. org/10.1210/jc.2011-3133)

Guigon CJ, Mazaud S, Forest MG, Brailly-Tabard S, Coudouel N \& Magre S 2003 Unaltered development of the initial follicular waves and normal pubertal onset in female rats after neonatal deletion of the follicular reserve. Endocrinology 144 3651-3662. (https://doi. org/10.1210/en.2003-0072)

Hagen CP, Aksglaede L, Sørensen K, Main KM, Boas M, Cleemann L, Holm K, Gravholt CH, Andersson A-M, Pedersen AT, et al. 2010 Serum levels of anti-Müllerian hormone as a marker of ovarian function in 926 healthy females from birth to adulthood and in 172 Turner syndrome patients. Journal of Clinical Endocrinology and Metabolism 95 5003-5010. (https://doi.org/10.1210/ jc.2010-0930)

Halpin DM, Jones A, Fink G \& Charlton HM 1986 Postnatal ovarian follicle development in hypogonadal (hpg) and normal mice and associated changes in the hypothalamic-pituitary ovarian axis. Journal of Reproduction and Fertility 77 287-296. (https://doi.org/10.1530/ jrf.0.0770287)

Hardy K, Fenwick M, Mora J, Laird M, Thomson K \& Franks S 2016 Onset and heterogeneity of responsiveness to FSH in mouse preantral follicles in culture. Endocrinology 158 134-147. (https://doi org/10.1210/en.2016-1435)

Hirshfield AN \& DeSanti AM 1995 Patterns of ovarian cell proliferation in rats during the embryonic period and the first three weeks postpartum. Biology of Reproduction 53 1208-1221. (https://doi. org/10.1095/biolreprod53.5.1208)

Jeppesen JV, Anderson RA, Kelsey TW, Christiansen SL, Kristensen SG, Jayaprakasan K, Raine-Fenning N, Campbell BK \& Yding Andersen C 2013 Which follicles make the most anti-Mullerian hormone in humans? Evidence for an abrupt decline in AMH production at the time of follicle selection. Molecular Human Reproduction 19 519-527. (https://doi.org/10.1093/molehr/gat024)

Kuiri-Hänninen T, Kallio S, Seuri R, Tyrväinen E, Liakka A, Tapanainen J, Sankilampi U \& Dunkel L 2011 Postnatal developmental changes in the pituitary-ovarian axis in preterm and term infant girls. Journal of Clinical Endocrinology and Metabolism 96 3432-3439. (https://doi. org/10.1210/jc.2011-1502)

Kuiri-Hänninen T, Haanpää M, Turpeinen U, Hämäläinen E, Seuri R, Tyrväinen E, Sankilampi U \& Dunkel L 2013 Postnatal ovarian activation has effects in estrogen target tissues in infant girls. Journal of Clinical Endocrinology and Metabolism 98 4709-4716. (https://doi. org/10.1210/jc.2013-1677)

Kuiri-Hänninen T, Sankilampi U \& Dunkel L 2014 Activation of the hypothalamic-pituitary-gonadal axis in infancy: minipuberty. Hormone Research in Paediatrics 82 73-80. (https://doi. org/10.1159/000362414)

Mazaud S, Guigon CJ, Lozach A, Coudouel N, Forest MG, Coffigny H \& Magre S 2002 Establishment of the reproductive function and transient fertility of female rats lacking primordial follicle stock after fetal gamma-irradiation. Endocrinology 143 4775-4787. (https://doi. org/10.1210/en.2002-220464)

McGee EA, Perlas E, LaPolt PS, Tsafriri A \& Hsueh AJ 1997 Folliclestimulating hormone enhances the development of preantral follicles in juvenile rats. Biology of Reproduction 57 990-998. (https://doi. org/10.1095/biolreprod57.5.990)

Mork L, Maatouk DM, McMahon JA, Guo JJ, Zhang P, McMahon AP \& Capel B 2012 Temporal differences in granulosa cell specification in the ovary reflect distinct follicle fates in mice. Biology of Reproduction 86 37. (https://doi.org/10.1095/biolreprod.111.095208) 
O'Shaughnessy PJ, McLelland D \& McBride MW 1997 Regulation of luteinizing hormone-receptor and follicle-stimulating hormonereceptor messenger ribonucleic acid levels during development in the neonatal mouse ovary. Biology of Reproduction 57 602-608. (https:// doi.org/10.1095/biolreprod57.3.602)

Pedersen T 1969 Follicle growth in the immature mouse ovary. Acta Endocrinologica 62 117-132. (https://doi.org/10.1530/acta.0.0620117)

Pellatt L, Rice S, Dilaver N, Heshri A, Galea R, Brincat M, Brown K, Simpson ER \& Mason HD 2011 Anti-Müllerian hormone reduces follicle sensitivity to follicle-stimulating hormone in human granulosa cells. Fertility and Sterility 96 1246.e1-1251.e1. (https://doi. org/10.1016/j.fertnstert.2011.08.015)

Prapa E, Vasilaki A, Dafopoulos K, Katsiani E, Georgoulias P, Messini CI, Anifandis G \& Messinis IE 2015 Effect of Anti-Müllerian hormone $(\mathrm{AMH})$ and bone morphogenetic protein 15 (BMP-15) on steroidogenesis in primary-cultured human luteinizing granulosa cells through Smad5 signalling. Journal of Assisted Reproduction and Genetics 32 1079-1088. (https://doi.org/10.1007/s10815-015-0494-2)

Rey RA 2014 Mini-puberty and true puberty: differences in testicular function. Annales D'endocrinologie 75 58-63. (https://doi. org/10.1016/j.ando.2014.03.001)

Richards JS, Sharma SC, Falender AE \& Lo YH 2002 Expression of FKHR, FKHRL1, and AFX genes in the rodent ovary: evidence for regulation by IGF-I, estrogen, and the gonadotropins. Molecular Endocrinology 16 580-599. (https://doi.org/10.1210/mend.16.3.0806)

Roy S, Gandra D, Seger C, Biswas A, Kushnir VA, Gleicher N, Kumar TR \& Sen A 2018 Oocyte-derived factors (GDF9 and BMP15) and FSH regulate AMH expression via modulation of H3K27AC in granulosa cells. Endocrinology 159 3433-3445. (https://doi.org/10.1210/en.2018-00609)

Sacchi S, D’Ippolito G, Sena P, Marsella T, Tagliasacchi D, Maggi E, Argento C, Tirelli A, Giulini S \& La Marca A 2016 The anti-Müllerian hormone $(\mathrm{AMH})$ acts as a gatekeeper of ovarian steroidogenesis inhibiting the granulosa cell response to both FSH and LH. Journal of
Assisted Reproduction and Genetics 33 95-100. (https://doi.org/10.1007/ s10815-015-0615-y)

Stewart J \& Cygan D 1980 Ovarian hormones act early in development to feminize adult open-field behavior in the rat. Hormones and Behavior 14 20-32. (https://doi.org/10.1016/0018-506X(80)90012-4)

Taieb J, Grynberg M, Pierre A, Arouche N, Massart P, Belville C, Hesters L, Frydman R, Catteau-Jonard S, Fanchin R, et al. 2011 FSH and its second messenger cAMP stimulate the transcription of human anti-Müllerian hormone in cultured granulosa cells. Molecular Endocrinology 25 645-655. (https://doi.org/10.1210/me.2010-0297)

Torres-Rovira L, Succu S, Pasciu V, Manca ME, Gonzalez-Bulnes A, Leoni GG, Pennino MG, Spezzigu A, Gallus M, Dattena M, et al. 2016 Postnatal pituitary and follicular activation: a revisited hypothesis in a sheep model. Reproduction 151 215-225. (https://doi.org/10.1530/ REP-15-0316)

Visser JA \& Themmen APN 2014 Role of anti-Müllerian hormone and bone morphogenetic proteins in the regulation of FSH sensitivity. Molecular and Cellular Endocrinology 382 460-465. (https://doi. org/10.1016/j.mce.2013.08.012)

White SS \& Ojeda SR 1981 Changes in ovarian luteinizing hormone and follicle-stimulating hormone receptor content and in gonadotropininduced ornithine decarboxylase activity during prepubertal and pubertal development of the female rat. Endocrinology 109 152-161. (https://doi.org/10.1210/endo-109-1-152)

Winter JS, Faiman C, Hobson WC, Prasad AV \& Reyes FI 1975 Pituitarygonadal relations in infancy. I. Patterns of serum gonadotropin concentrations from birth to four years of age in man and chimpanzee. Journal of Clinical Endocrinology and Metabolism $\mathbf{4 0}$ 545-551. (https://doi.org/10.1210/jcem-40-4-545)

Zheng W, Zhang H, Gorre N, Risal S, Shen Y \& Liu K 2014 Two classes of ovarian primordial follicles exhibit distinct developmental dynamics and physiological functions. Human Molecular Genetics 23 920-928. (https://doi.org/10.1093/hmg/ddt486)

Received in final form 15 October 2018

Accepted 5 November 2018

Accepted Preprint published online 7 November 2018 (c) 2019 Society for Endocrinology Published by Bioscientifica Ltd. Printed in Great Britain 